\title{
Enantioselective reduction of ketoimines promoted by easily available (S)-proline derivatives
}

\author{
Martina Bonsignore ${ }^{1}$, Maurizio Benaglia ${ }^{* 1, \S}$, Laura Raimondi ${ }^{1}$, \\ Manuel Orlandi ${ }^{1}$ and Giuseppe Celentano ${ }^{2}$
}

\author{
Letter \\ Address: \\ ${ }^{1}$ Dipartimento di Chimica, Università degli Studi di Milano, via Golgi \\ 19, I-20133 Milano, Italy and ${ }^{2}$ Dipartimento di Scienze \\ Farmaceutiche, Università degli Studi di Milano, Via Mangiagalli 25, \\ 20133, Milano, Italy \\ Email: \\ Maurizio Benaglia* - maurizio.benaglia@unimi.it \\ * Corresponding author \\ § Tel.: +39025031-4171; Fax: +39025031-4159 \\ Keywords: \\ chiral prolines; imine reduction; Lewis bases; organocatalysis; \\ trichlorosilane
}

Beilstein J. Org. Chem. 2013, 9, 633-640.

doi:10.3762/bjoc.9.71

Received: 16 January 2013

Accepted: 08 March 2013

Published: 02 April 2013

Associate Editor: M. Rueping

(C) 2013 Bonsignore et al; licensee Beilstein-Institut. License and terms: see end of document.

\begin{abstract}
The behavior of readily synthesized and even commercially available $(S)$-proline derivatives, was studied in the trichlorosilanemediated reduction of ketoimines. A small library of structurally and electronically modified chiral Lewis bases was considered; such compounds were shown to promote the enantioselective reduction of different substrates in good chemical yields. In the $\mathrm{HSiCl}_{3}$ addition to the model substrate $N$-phenylacetophenone imine, the organocatalyst of choice led to the formation of the corresponding amine with good stereoselectivity, up to $75 \%$ ee. Theoretical studies were also performed in order to elucidate the origin of the stereoselection.
\end{abstract}

\section{Introduction}

The reaction with stoichiometric amounts of trichlorosilane in the presence of a chiral catalyst is a well-established methodology to perform enantioselective reductions of carbon nitrogen double bonds [1]. In the past decade different classes of enantiomerically pure Lewis bases have been developed, including $N$-formyl derivatives, oxazolines, imidazole derivatives, sulfonamides and picolinamides [2,3]. Some of these successful catalysts essentially owe their stereodirecting ability to the steric shielding exerted by a proper spatial arrangement of the structural components (Figure 1); this is the case for example for Malkov and Kocovsky catalyst [4] A or Jones catalyst $\mathbf{B}[5,6]$ or the binaphthyldiamine-derived catalyst $\mathbf{C}$ developed by our group [7,8]. Also in other systems, such as the Matsumura-type catalysts developed by Zhang [9] of type $\mathbf{D}$, the presence of a proper sterically hindered element seems to be much more decisive than the ability of the tertiary alcohol to make a possible, but not probable, weak hydrogen bond. 
<smiles>[PH2+]c1cccnc1</smiles>

catalyst type $\mathbf{A}$

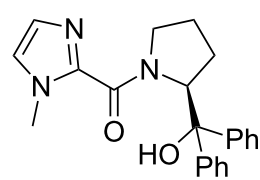

catalyst type B<smiles>CNc1ccc2ccccc2c1-c1c(N(C)C)ccc2ccccc12</smiles>

catalyst type C<smiles>O=C(c1ccccn1)N1C[C@H](O[Na])C[C@H]1C(O)(c1ccccc1)c1ccccc1</smiles>

catalyst type D

Figure 1: Catalysts of types A-D.

However, most of the more efficient systems rely on the presence of catalyst-substrate hydrogen bonding as a key structural element in controlling the stereoselectivity of the process (Figure 2). In the $N$-formyl valine derivative $\mathbf{E}[10,11]$ the proposed transition-state structure involves the formation of a hydrogen-bond between the amide group of the catalyst and the substrate as a necessary element for stereocontrol (for another example of relevant $N$-formyl proline derivative see [12]). Also in Sun catalysts $\mathbf{F}[13,14]$ and sulfinamide $\mathbf{G}[15]$ as well as in chiral picolinamides $\mathbf{H}$, reported by Zhang $[16,17]$ and intensely studied by our group [18-23], the presence of the acidic hydrogen of the amide group is essential for the stereochemical efficiency of the metal-free catalyst.

Based on these considerations we decided to investigate the use of a strong hydrogen-bond donor functionality as the carboxylic acid group; it is worth mentioning that also phosphoric acid catalyzed reductions of $\mathrm{C}=\mathrm{N}$ bonds with Hantzsch ester involve the coordination and activation of the substrate through the formation of a H-bond between the hydrogen atom of the phosphoric acid and the nitrogen atom of the imine [24-26]. However, we were attracted by a recent work by Arndtsen, who demonstrated that coupling metal catalysis and the ability of amino acids to form hydrogen bonds provides an easy route for inducing both enantioselectivity and selectivity (left picture in Figure 3) [27]. A simple combination of amino acid and copper catalyst provided an easily tunable system for synthesizing a range of propargylamines with high enantioselectivity. A key element of the elevate enantioselectivity was the hydrogen bonding between the chiral amino acid and the substrate, while high selectivity was achieved by tuning the metal catalyst. In the trichlorosilane-mediated reductions in this work we aimed to exploit the imine activation by the acid proton of the carboxylic group, which can act at the same time as a Lewis basic site to coordinate the silicon atom and hopefully control the stereoselectivity of the process (right picture in Figure 3).

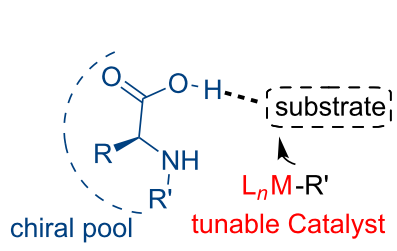

Arndtsen approach

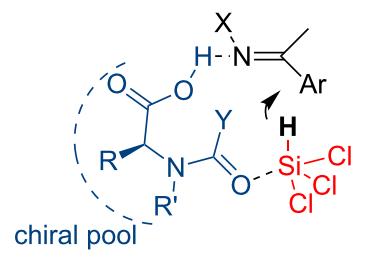

our approach
Figure 3: Proposed approach in this work

It should be mentioned that Matsumura already in 2006 reported that trichlorosilane may be employed in the stereoselective reduction of ketones [28]. Catalytic amounts of $N$-formyl- $\alpha$-(2,4,6-triethylphenyl)-( $S$ )-proline in combination with stoichiometric trichlorosilane allowed the formation of secondary alcohols with high levels of enantioselection (up to $97 \%$, Scheme 1), which was strongly influenced both by the carboxylic group at the $\alpha$-position and the 2,4,6-triethylphenyl group at the 5-position in the proline ring. It must be noted, however, that the successful catalyst is not an easily available<smiles>[R]c1cc([R])cc(NC(=O)C(C(C)C)N(C)C([2H])=O)c1</smiles>

catalyst type $\mathbf{E}$<smiles></smiles>

catalyst type $\mathbf{F}$<smiles>Cc1cc(C)cc(NC(=O)C2CCCN2[SH](O)C(C)(C)C)c1</smiles>

catalyst type $\mathbf{G}$<smiles>[R]c1ccc(C(=O)N([C@@H](C)c2ccccc2)[C@@H](C)[C@H](O)c2ccccc2)nc1</smiles>

catalyst type $\mathbf{H}$ 


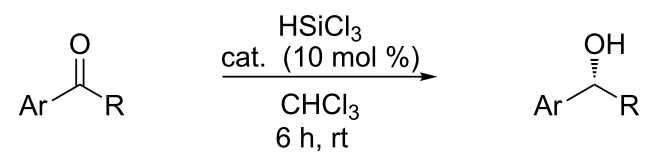

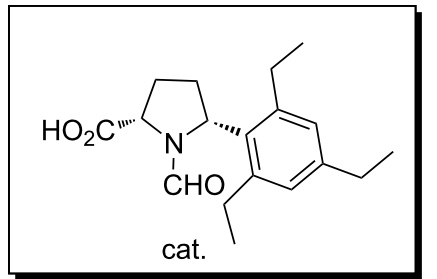

Scheme 1: Stereoselective reduction of ketones.

compound and, in that work, no examples of carbon-nitrogen double-bond reduction were described.

\section{Results and Discussion}

In our approach we decided to investigate very simple chiral carboxylic acids, and we turned our attention to the most obvious source of enantiopure acids, i.e., the natural amino acids. The development of readily available catalysts, synthesized in a few steps starting from inexpensive commercial sources is a long standing but still topical goal of modern asymmetric catalysis. At the beginning of this study we focused on the synthesis of very simple proline derivatives; therefore a small library of electronically and structurally different $(S)$ proline derivatives, including a few immediately available, commercial products, were easily prepared, with simple modifications at the amino acid nitrogen atom.

We decided to start our investigation testing the commercially available $N$-Boc-L-proline (1) as catalyst in the reduction of ketimines with trichlorosilane. The imines were typically prepared with a microwave-promoted reaction between aceto- phenone and the aromatic amine in toluene in the presence of $\mathrm{K} 10$ clay as activator.

The first screening allowed us to determine the best catalyst loading and the solvent of choice. Different experimental conditions and reaction temperatures were investigated. A few selected results are reported in Table 1.

These preliminary data showed that the appropriate catalyst loading seemed to be $30 \mathrm{~mol} \%$ to achieve good yield after 18 hours. Under these conditions a modest to good level of stereoselection were observed; the best results were obtained by running the reaction in chlorinated solvents, such as dichloromethane and chloroform, where enantioselectivity up to $75 \%$ was achieved by simply performing the reduction at $0{ }^{\circ} \mathrm{C}$.

The easy one-step reaction between $(S)$-proline and various acyl chlorides, in the presence of $1 \mathrm{~N} \mathrm{NaOH}$, allowed the formation of the catalysts illustrated in Figure 4. The acyl chlorides, when not commercially available, were prepared starting from the corresponding acid by treatment with thionyl chloride under

Table 1: Enantioselective reduction with catalyst $1 .^{a}$<smiles>C/C(=N\c1ccccc1)c1ccccc1</smiles>

\begin{tabular}{ccccccc}
\hline Entry & cat. 1 (\%) & solvent & $t(\mathrm{~h})$ & $T\left({ }^{\circ} \mathrm{C}\right)$ & yield $(\%)^{\mathrm{b}}$ \\
\hline 1 & 10 & $\mathrm{DCM}$ & 8 & 0 & 20 \\
2 & 20 & $\mathrm{DCM}$ & 18 & 0 & 74 \\
3 & 30 & $\mathrm{DCM}$ & 32 & -20 & 74 \\
4 & 30 & $\mathrm{CH}_{3} \mathrm{Cl}$ & 18 & 0 & 27 \\
5 & 30 & hexane & 18 & 0 & 25 \\
6 & 30 & toluene & 18 & 0 & 43 \\
\hline
\end{tabular}

aReaction conditions: imine $(0.33 \mathrm{mmol}), \mathrm{HSiCl}_{3}(1.15 \mathrm{mmol}) .{ }^{\text {bY }}$ ields determined after chromatographic purification. ${ }^{\mathrm{C}}$ Enantiomeric excess determined by HPLC on chiral stationary phase. 
<smiles>CC(C)(C)OC(=O)N1CCCC1C(=O)O</smiles>

1<smiles>O=C(O)C1CCCN1C(=O)c1ccccc1</smiles>

6<smiles>Cc1cc(C)cc(C(=O)N2CCCC2C(=O)O)c1</smiles>

11<smiles>O=C(O)[C@@H]1CC(O)CN1C(=O)c1ccccc1</smiles><smiles>O=CC1CCCN1C=O</smiles>

2<smiles>O=C(O)C1CCCN1C(=O)c1ccccn1</smiles>

7<smiles>O=C(O)C1CCCN1C(=O)c1cc(C(F)(F)F)cc(C(F)(F)F)c1</smiles>

12<smiles>O=C(O)[C@@H]1CCCN1C(=O)OCc1ccccc1</smiles>

4<smiles>Cc1cc(C)c(C(=O)N2CCCC2C(=O)O)c(C)c1</smiles><smiles>O=C(O)C1CCCN1C(=O)c1cccc2ccccc12</smiles>

14<smiles>CC(C)(C)C(=O)N1CCCC1C(=O)O</smiles><smiles>COc1ccc(C(=O)N2CCCC2C(=O)O)c(OC)c1</smiles>
10<smiles>CC1(C)C2CCC1(CS(=O)(=O)N1CCCC1C(=O)O)C(=O)C2</smiles><smiles>O=C(O)[C@H]1CCCN1C(=O)c1c(F)c(F)c(F)c(F)c1F</smiles>

13<smiles>CO[C@H]1C[C@@H](C(=O)O)N(C(=O)c2ccccc2)C1</smiles>

Figure 4: Catalysts synthesized and studied in this work.

reflux for 4 hours. The catalytic efficiency of these catalysts was evaluated in the stereoselective reduction of the $N$-phenyl imine of acetophenone (Table 2).

After running the reaction in dichloromethane at $0{ }^{\circ} \mathrm{C}$ for 18 hours, all the catalysts afforded the desired product in modest to good yields. The $N$-formyl-L-proline (2) led to a racemic product in $21 \%$ yield, suggesting the importance of having a bulky group on the nitrogen atom. In order to validate our hypothesis, we also tested the $N$-Boc-L-proline methyl ester (3): the enantiomeric excess was $19 \%$ and the yield was $49 \%$. The outcome of this experiment strongly suggested the importance of hydrogen bonding between the catalyst and the substrate in the stereodetermining event.

By using catalysts $\mathbf{6}$ and $\mathbf{1 1}$ the amine was isolated with good chemical efficiency ( $63 \%$ and $74 \%$ yield) and discrete level of enantioselection, i.e., $59 \%$ and $62 \%$ ee, respectively. Increasing the steric hindrance on the aromatic ring did not improve the enantioselectivity and it generally lowered the chemical activity. A pyridine ring had no positive effect on the process in terms of stereocontrol (Table 2, entry 7), probably due to its coordination ability to the silicon atom, leading to multiple possible coordination modes of trichlorosilane, which are detrimental for the determination of a well-defined activation of the reducing agent and a control of the stereoselectivity.
Table 2: Enantioselective reduction of the $\mathrm{N}$-phenyl imine of acetophenone. $^{a}$

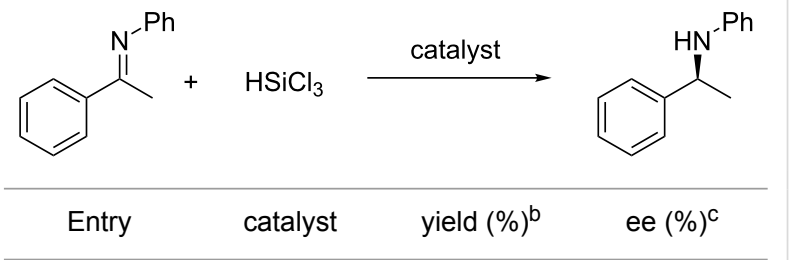

\begin{tabular}{cccc}
\hline 1 & $\mathbf{1}$ & 74 & 51 \\
2 & $\mathbf{2}$ & 21 & rac \\
3 & $\mathbf{3}$ & 49 & 19 \\
4 & $\mathbf{4}$ & 25 & 49 \\
5 & $\mathbf{5}$ & 36 & 70 \\
6 & $\mathbf{6}$ & 63 & 59 \\
7 & $\mathbf{7}$ & 98 & 11 \\
8 & $\mathbf{8}$ & 56 & 30 \\
9 & $\mathbf{9}$ & 54 & 34 \\
10 & $\mathbf{1 0}$ & 30 & 27 \\
11 & $\mathbf{1 1}$ & 74 & 62 \\
12 & $\mathbf{1 3}$ & 10 & $8(R)$ \\
13 & $\mathbf{1 4}$ & 30 & 32 \\
14 & 16 & 26 & rac \\
15 & $\mathbf{1 7}$ & 71 & 66 \\
\hline
\end{tabular}

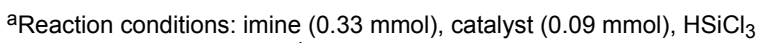
(1.15 mmol); $0{ }^{\circ} \mathrm{C}$ in DCM. bYields determined after chromatographic purification. 'Enantiomeric excess determined by HPLC on chiral stationary phase. 
Notably, catalyst 5, with the pivaloyl group at the nitrogen atom, afforded the product with $36 \%$ yield and $70 \%$ enantiomeric excess. The presence of a hydroxy group on the scaffold of the catalyst (cat. 16, Table 2, entry 14) led to a racemic product, while the silyl ether derivative (17, Table 2 , entry 15$)$ promoted the reaction with good enantioselectivity, showing that the hydroxy group may act as a competitive site of coordination for trichlorosilane.

Driven by these results, we focused on a more in-depth study of the most promising system. Catalysts $\mathbf{5}$ and $\mathbf{6}$ were selected to investigate the substrate scope in the enantioselective reduction of differently substituted imines (Table 3).

Catalyst 5 showed a good chemical activity, promoting the enantioselective reduction in yields up to $88 \%$, except when a very bulky protecting group was used (Table 3 , entry 4 ). In the reaction of both $N$-Ph and $N$-PMP imines derived from acetophenone a discrete level of enantioselectivity was achieved, leading to $70 \%$ and $68 \%$ enantioselectivity, respectively. Analogously, the reduction of imine derived from 4-trifluoromethylacetophenone, led to the product in $77 \%$ ee. A remarkable drop in enantioselectivity was observed when the imine derived from propiophenone was employed (Table 3, entry 5).

Catalyst 6 followed essentially the same trend: the chemical activity was good, but no improvement of the stereochemical efficiency of the catalyst was observed. Indeed the best result was achieved on performing the reaction with the $N-\mathrm{Ph}$ imine derived from acetophenone, with $63 \%$ yield and $59 \%$ ee (Table 3, entry 6).
Theoretical studies were also performed in order to elucidate the origin of the stereoselection. The reaction of $N$-phenyl imine of acetophenone with trichlorosilane promoted by catalyst $\mathbf{6}$, i.e., the one that afforded higher yields and enantioselectivities (Table 3), was studied, and the two lowest energy transition states (TS) leading to the formation of $R$ and $S$ amine were located. In order to simplify the problem, we adopted a stepwise procedure for the location of the TS structures. First of all, a conformational analysis with Monte Carlo techniques was performed with MMFF [29] on a simple model of the TS, obtained by constraining the two reacting atoms (the hydride and the imine's carboxylic carbon) at about $2.4 \AA$. In this way, the best arrangement for the different substituents around a model of the reaction moiety was obtained. Subsequently, the two lowest energy structures leading to the formation of the $R$ and $S$ products, respectively, were optimized to the relative TSs with HF/3-21G ab-initio methods [30]. After vibrational characterization of these structures (both with only one imaginary frequency), they were fully re-optimized with DFT methods [30]: optimization and calculation of the thermochemical properties was performed with M06-2X [31] functional and 6-31G basis-set (M06-2X structures are reported in Figure 5), while finer electronic energies were calculated with the $6-311 \mathrm{G}(2 \mathrm{~d}, \mathrm{p})$ basis-set on the $6-31 \mathrm{G}$ structures. IRC calculations were also performed at the HF/3-21G level [31].

Inspection of the imaginary frequency of the two TSs, as well as IRC results, clearly indicates that the reaction, while not synchronous, is indeed concerted, since proton and hydride transfer are both occurring: while the proton transfer from the carboxylic group to the imine nitrogen is almost complete, the

Table 3: Enantioselective reduction of differently substituted imines. ${ }^{a}$

\begin{tabular}{|c|c|c|c|c|c|c|}
\hline \multirow[b]{2}{*}{ Entry } & \multirow[b]{2}{*}{ catalyst } & \multirow{2}{*}{$\mathrm{R}^{+}$} & \multirow{2}{*}{ 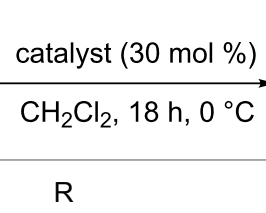 } & \multirow{2}{*}{\multicolumn{2}{|c|}{ yield $(\%)^{b}$}} & \multirow[b]{2}{*}{ ee $(\%)^{c}$} \\
\hline & & & & & & \\
\hline 1 & 5 & $\mathrm{Ph}$ & $\mathrm{CH}_{3}$ & $\mathrm{Ph}$ & 36 & 70 \\
\hline 2 & 5 & $\mathrm{Ph}$ & $\mathrm{CH}_{3}$ & PMP & 76 & 68 \\
\hline 3 & 5 & $4-\mathrm{CF}_{3} \mathrm{Ph}$ & $\mathrm{CH}_{3}$ & $\mathrm{Ph}$ & 55 & 77 \\
\hline 4 & 5 & 1-naphthyl & $\mathrm{CH}_{3}$ & $\mathrm{Ph}$ & 88 & 59 \\
\hline 5 & 5 & $\mathrm{Ph}$ & $\mathrm{CH}_{2} \mathrm{CH}_{3}$ & $\mathrm{Ph}$ & 79 & 5 \\
\hline 6 & 6 & $\mathrm{Ph}$ & $\mathrm{CH}_{3}$ & $\mathrm{Ph}$ & 63 & 59 \\
\hline 7 & 6 & $\mathrm{Ph}$ & $\mathrm{CH}_{3}$ & PMP & 79 & 55 \\
\hline 8 & 6 & $4-\mathrm{CF}_{3} \mathrm{Ph}$ & $\mathrm{CH}_{3}$ & $\mathrm{Ph}$ & 83 & 49 \\
\hline 9 & 6 & 1-naphthyl & $\mathrm{CH}_{3}$ & $\mathrm{Ph}$ & 80 & 55 \\
\hline 10 & 6 & $\mathrm{Ph}$ & $\mathrm{CH}_{2} \mathrm{CH}_{3}$ & $\mathrm{Ph}$ & 85 & 53 \\
\hline
\end{tabular}

aReaction conditions: imine $(0.33 \mathrm{mmol})$, catalyst $(0.09 \mathrm{mmol}), \mathrm{HSiCl}_{3}(1.15 \mathrm{mmol}), 0{ }^{\circ} \mathrm{C}, \mathrm{DCM}$. byields determined after chromatographic purification. 'Enantiomeric excess determined by HPLC on chiral stationary phase. 

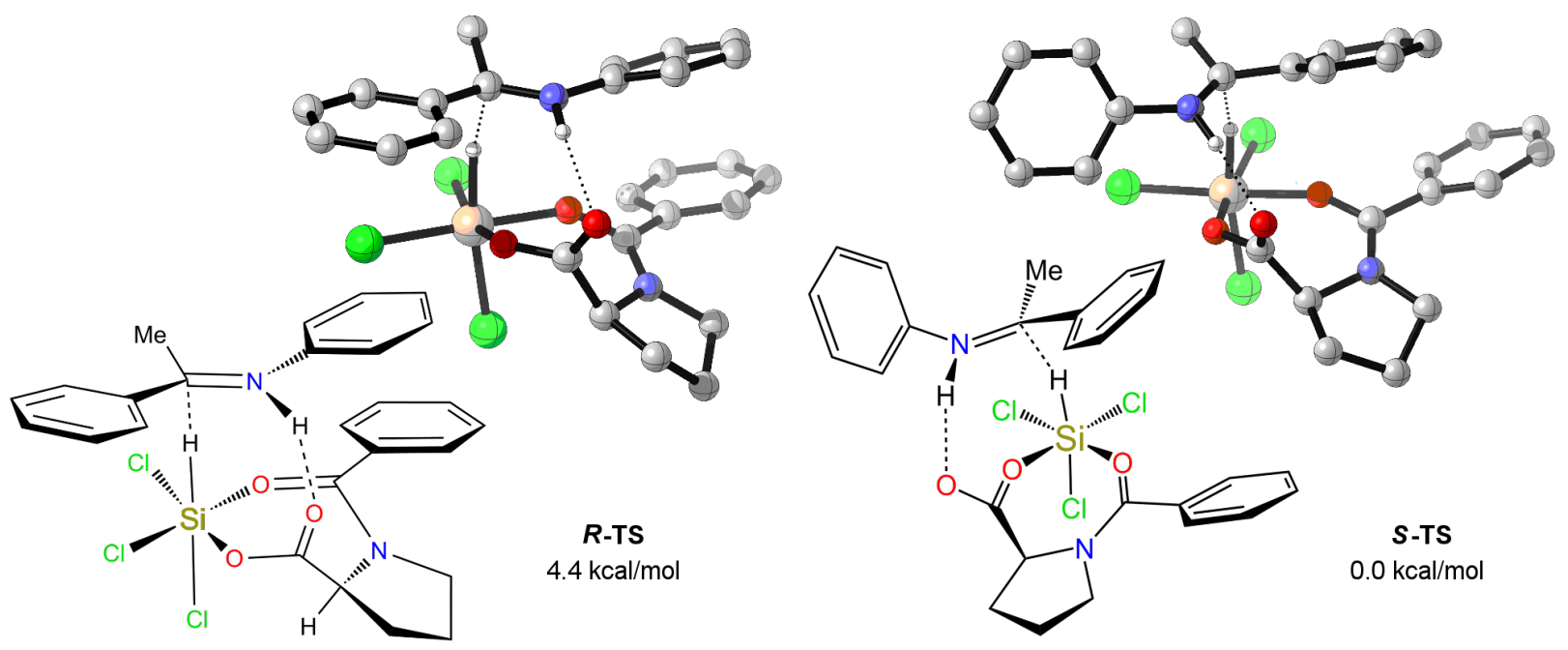

Figure 5: Calculated transition states for catalyst 6 .

hydride transfer is still early, leading to a reaction classifiable as a counteranion-directed catalytic process [32]. The hydrogen bond between the proline carboxylate and the $\mathrm{NH}^{+}$residues guarantees the proximity of all reactants. The calculations show the TS leading to the S-enantiomer to be more stable by 4.4 $\mathrm{kcal} / \mathrm{mol}$, which is in qualitative agreement with the experimental data.

\section{Conclusion}

In conclusion, a series of enantiomerically pure Lewis bases directly derived from commercially available enantiopure $(S)$ proline or its derivatives was synthesized and tested in the stereoselective reduction of ketoimines in the presence of trichlorosilane. It is noteworthy that some of these catalysts are commercially available compounds and were shown to be able to promote the reaction in high chemical yield. Although the level of enantioselectivity reached in the reduction of $\mathrm{N}$-phenylacetophenone imine was not comparable with those of the best catalyst (ee up to $75 \%$ ), the low cost and the easy preparation of the chiral catalysts makes these proline-derived Lewis bases suitable candidates as starting materials for further studies and developments.

\section{Experimental}

General Methods. TLC was performed on Merck silica gel 60 TLC plates F254 and visualized by using UV or phosphomolybdic acid. Flash chromatography was carried out on silica gel (230-400 mesh). ${ }^{1} \mathrm{H}$ NMR spectra were recorded at $300 \mathrm{MHz}$ with the indicated solvent. ${ }^{13} \mathrm{C}$ NMR spectra were obtained at $75 \mathrm{MHz}$. Chemical shifts were determined relative to tetramethylsilane (for hydrogen atoms) and residual solvent peaks (for carbon atoms). Optical rotations were obtained on a Perkin-Elmer 241 polarimeter at $589 \mathrm{~nm}$. HPLC for ee determination was performed on Agilent 1100 instrument under the conditions reported below. Force field conformational analysis was performed with the Schroedinger suite MacroModel. Ab initio and DFT calculations were performed with Gaussian09 [33]. Frequency calculations allowed for characterization as such of the transition structures and for calculation of ZPE-corrected free energies.

\section{Catalysts preparation}

General procedure: $(S)$-Proline $(2.7 \mathrm{mmol})$ was dissolved in $5 \mathrm{~mL}$ of $1 \mathrm{~N} \mathrm{NaOH}$, cooled to $0{ }^{\circ} \mathrm{C}$ in an ice-water bath and stirred magnetically. The acyl chloride $(3 \mathrm{mmol})$ dissolved in THF and $2.5 \mathrm{~mL}$ of $1 \mathrm{~N} \mathrm{NaOH}$ were added over the course of 15 min through a dropping funnel, with the temperature maintained at $5-10{ }^{\circ} \mathrm{C}$. The $\mathrm{pH}$ was checked periodically to ensure that the solution remained strongly alkaline. After the addition was complete, the reaction mixture was allowed to warm to room temperature and stirred vigorously overnight. To the basic solution was added $1 \mathrm{~N} \mathrm{HCl}$ until the $\mathrm{pH}$ became slightly acidic. Then the solution was extracted with DCM, and the organic layers were combined, dried over anhydrous $\mathrm{MgSO}_{4}$, concentrated on a rotary evaporator, and purified.

Catalyst 5. This product was purified by flash column chromatography on silica gel with 8:2 hexane/AcOEt as eluent. Yield 29\%. ${ }^{1} \mathrm{H}$ NMR $\left(300 \mathrm{MHz}, \mathrm{CDCl}_{3}\right) \delta 4.42(\mathrm{~m}, 1 \mathrm{H}), 3.53(\mathrm{~m}$, $1 \mathrm{H}), 1.98(\mathrm{~m}, 2 \mathrm{H}), 1.81(\mathrm{~m}, 2 \mathrm{H}), 1.22(\mathrm{~s}, 9 \mathrm{H}) ;{ }^{13} \mathrm{C} \mathrm{NMR}$ $\left(75 \mathrm{MHz}, \mathrm{CDCl}_{3}\right) \delta 178.41(1 \mathrm{C}), 175.62$ (1C), 129.63 (1C), 61.54 (1C), 48.41 (1C), 38.91 (1C), 27.22 (3C), 26.82 (1C); 
$[\alpha]_{\mathrm{D}}^{25}-150.24\left(c 0.286 \mathrm{~g} / 100 \mathrm{~mL}, \mathrm{CHCl}_{3}\right)$; ESIMS $m / z(\%)$ : calcd for $\mathrm{C}_{10} \mathrm{H}_{17} \mathrm{NO}_{3}, 119.2$; found, 119.0

Catalyst 6. This product was purified by flash column chromatography on silica gel with a 95:5 $\mathrm{DCM} / \mathrm{MeOH}$ mixture as eluent. Yield quantitative. ${ }^{1} \mathrm{H}$ NMR $\left(200 \mathrm{MHz}, \mathrm{CDCl}_{3}\right) \delta 7.32$ (m, 5H), $4.65(\mathrm{dd}, 1 \mathrm{H}), 3.53(\mathrm{~m}, 2 \mathrm{H}), 2.00(\mathrm{~m}, 4 \mathrm{H}) ;{ }^{13} \mathrm{C} \mathrm{NMR}$ $\left(75 \mathrm{MHz}, \mathrm{CDCl}_{3}\right) \delta 174.97$ (1C), 170.71(1C), 135.5 (1C), 130.47 (1C), 128.27 (2C), 127.21 (2C), 59.70 (1C), 50.25 (1C), 28.93 (1C), 25.16 (1C).

\section{Imine reduction}

General procedure: As described in [8]: to a stirred solution of catalyst $(0.1-0.3 \mathrm{~mol} \%)$ in the chosen solvent $(2 \mathrm{~mL})$, the imine $(1 \mathrm{mmol})$ was added. The mixture was then cooled to the chosen temperature and trichlorosilane $(3.5 \mathrm{mmol})$ was added dropwise by means of a syringe. After stirring at the appropriate temperature, the reaction was quenched by the addition of a saturated aqueous solution of $\mathrm{NaHCO}_{3}(1 \mathrm{~mL})$. The mixture was allowed to warm up to room temperature, and water $(2 \mathrm{~mL})$ and dichloromethane $(5 \mathrm{~mL})$ were added. The organic phase was separated and the combined organic phases were dried over $\mathrm{Na}_{2} \mathrm{SO}_{4}$, filtered, and concentrated under vacuum at room temperature to afford the crude product. The amine was purified by flash chromatography and the absolute configuration was determined by comparison with literature data.

$\mathrm{N}$-(Phenyl)-1-phenylethanamine. This product was purified by flash column chromatography on silica gel with a 98:2 hexane/ ethyl acetate mixture as eluent. ${ }^{1} \mathrm{H} \mathrm{NMR}\left(300 \mathrm{MHz}, \mathrm{CDCl}_{3}\right) \delta$ $7.23(\mathrm{~m}, 7 \mathrm{H}), 6.61(\mathrm{~m}, 3 \mathrm{H}), 4.48(\mathrm{q}, 1 \mathrm{H}), 1.53(\mathrm{~d}, 3 \mathrm{H})$. The enantiomeric excess was determined by HPLC on a Chiralcel OD-H $\left(n-\mathrm{Hex} / \mathrm{iPrOH} 99: 1 ; 0.8 \mathrm{~mL} / \mathrm{min} ; t_{\mathrm{R}}(S)=15.4 \mathrm{~min} ; t_{\mathrm{R}}\right.$ $(R)=18.5 \mathrm{~min})$.

$\mathrm{N}$-(1-Phenylpropyl)aniline. This product was purified with a 98:2 hexane/ethyl acetate mixture as eluent. ${ }^{1} \mathrm{H}$ NMR $\left(300 \mathrm{MHz}, \mathrm{CDCl}_{3}\right) \delta 7.31(\mathrm{~m}, 4 \mathrm{H}), 7.21(\mathrm{~m}, 1 \mathrm{H}), 7.07(\mathrm{t}, 2 \mathrm{H})$, $6.62(\mathrm{t}, 1 \mathrm{H}), 6.50(\mathrm{~d}, 2 \mathrm{H}), 4.21(\mathrm{t}, 1 \mathrm{H}), 4.05(\mathrm{br} \mathrm{s}, 1 \mathrm{H}), 1.81(\mathrm{~m}$, 2H), 0.94 (t, 3H); HPLC: Chiralcel IB; $n-\mathrm{Hex} / \mathrm{iPrOH} 99: 1 ; 0.8$ $\mathrm{mL} / \mathrm{min} ; t_{\mathrm{R}}(S)=7.9 \mathrm{~min}, t_{\mathrm{R}}(R)=8.5 \mathrm{~min}$.

$\mathrm{N}$-(1-(Naphthalen-2-yl)ethyl)aniline. This product was purified with a hexane/ethyl acetate 98:2 mixture as eluent. ${ }^{1} \mathrm{H}$ NMR $\left(300 \mathrm{MHz}, \mathrm{CDCl}_{3}\right) \delta 7.89(\mathrm{~m}, 4 \mathrm{H}), 7.5(\mathrm{~m}, 3 \mathrm{H}), 7.1(\mathrm{t}$, 2H), $6.7(\mathrm{~m}, 3 \mathrm{H}), 4.6(\mathrm{q}, 1 \mathrm{H}), 3.97(\mathrm{br} \mathrm{s}, 1 \mathrm{H}), 1.6(\mathrm{~d}, 3 \mathrm{H})$; HPLC: Chiralcel OD; $n$-Hex/iPrOH 99:1; $0.8 \mathrm{~mL} / \mathrm{min} ; t_{\mathrm{R}}(S)=$ $25.2 \mathrm{~min}, t_{\mathrm{R}}(R)=28.4 \mathrm{~min}$.

$\mathrm{N}$-(1-(4-(Trifluoromethyl)phenyl)ethyl)aniline. This product was purified with a 98:2 hexane/ethyl acetate mixture as eluent.
${ }^{1} \mathrm{H}$ NMR (300 MHz, $\left.\mathrm{CDCl}_{3}\right): \delta 7.51(\mathrm{~d}, 2 \mathrm{H}), 7.41(\mathrm{~d}, 2 \mathrm{H}), 7.02$ $(\mathrm{t}, 2 \mathrm{H}), 6.59(\mathrm{t}, 1 \mathrm{H}), 6.38(\mathrm{~d}, 2 \mathrm{H}), 4.46(\mathrm{q}, 1 \mathrm{H}), 3.97$ (br s, 1H), 1.46 (d, 3H); HPLC: Chiralcel OD; $n$-Hex/iPrOH 99:1; $0.8 \mathrm{~mL} /$ $\min ; t_{\mathrm{R}}(S)=29.3 \mathrm{~min}, t_{\mathrm{R}}(R)=35.7 \mathrm{~min}$.

4-Methoxy- $N$-(1-phenylethyl)aniline. This product was purified with a 98:2 hexane/ethyl acetate mixture as eluent. ${ }^{1} \mathrm{H}$ NMR $\left(300 \mathrm{MHz}, \mathrm{CDCl}_{3}\right) \delta 7.43-7.26(\mathrm{~m}, 5 \mathrm{H}), 6.73(\mathrm{~d}, 2 \mathrm{H})$, $6.58(\mathrm{~d}, 2 \mathrm{H}), 4.46(\mathrm{q}, 1 \mathrm{H}), 3.74(\mathrm{~s}, 3 \mathrm{H}), 1.58(\mathrm{~d}, 3 \mathrm{H})$; HPLC: Chiralcel IB; $n$-Hex/iPrOH 99:1; $0.8 \mathrm{~mL} / \mathrm{min} ; t_{\mathrm{R}}(S)=22.1 \mathrm{~min}$, $t_{\mathrm{R}}(R)=25.0 \mathrm{~min}$.

$\mathrm{N}$-Benzyl-1-phenylethanamine. This product was purified with an 8:2 hexane/ethyl acetate mixture as eluent. ${ }^{1} \mathrm{H}$ NMR $\left(300 \mathrm{MHz}, \mathrm{CDCl}_{3}\right) \delta 7.38-7.24(\mathrm{~m}, 10 \mathrm{H}), 3.82$ (q, 1H), 3.67, $3.60(\mathrm{AB}, 2 \mathrm{H}), 1.57$ (bs, 1H), 1.37 (d, 3H); HPLC: Chiralcel IB; $n$-Hex/iPrOH 99:1; $0.8 \mathrm{~mL} / \mathrm{min} ; t_{\mathrm{R}}(R)=8.8 \mathrm{~min}, t_{\mathrm{R}}(S)=9.4$ $\min$.

\section{Supporting Information}

\section{Supporting Information File 1}

Synthesis and NMR spectra of catalysts, selected HPLC

traces of the reduction products

[http://www.beilstein-journals.org/bjoc/content/

supplementary/1860-5397-9-71-S1.pdf]

\section{Acknowledgements}

Financial support by MIUR-PRIN (Rome) within the national project "Nuovi metodi catalitici stereoselettivi e sintesi stereoselettiva di molecole funzionali" is gratefully acknowledged. M. B. thanks COST action CM9505 "ORCA" Organocatalysis. We thank Prof. Franco Cozzi for helpful discussions.

\section{References}

1. Benaglia, M.; Genoni, A.; Bonsignore, M. Enantioselective organocatalytic reductions. In Stereoselective Organocatalysis; Rios, R., Ed.; Wiley: in press.

2. Guizzetti, S.; Benaglia, M. Eur. J. Org. Chem. 2010, 5529. doi:10.1002/ejoc.201000728

3. Jones, S.; Warner, C. J. A. Org. Biomol. Chem. 2012, 10, 2189. doi:10.1039/c2ob06854k

4. Malkov, A. V.; Stewart Liddon, A. J. P.; Ramirez-Lopez, P.; Bendova, L.; Haigh, D.; Kočovský, P. Angew. Chem., Int. Ed. 2006, 45, 1432. doi:10.1002/anie.200503941

5. Gautier, F.-M.; Jones, S.; Martin, S. J. Org. Biomol. Chem. 2009, 7, 229. doi:10.1039/b816051a

6. Gautier, F.-M.; Jones, S.; Li, X.; Martin, S. J. Org. Biomol. Chem. 2011, 9, 7860. doi:10.1039/C1OB05965C

7. Guizzetti, S.; Benaglia, M.; Celentano, G. Eur. J. Org. Chem. 2009, 3683. doi:10.1002/ejoc.200900524 
8. Guizzetti, S.; Benaglia, M.; Cozzi, F.; Rossi, S.; Celentano, G. Chirality 2009, 21, 233. doi:10.1002/chir.20615

9. Chen, X.; Zheng, Y.; Shu, C.; Yuan, W.; Liu, B.; Zhang, X. J. Org. Chem. 2011, 76, 9109. doi:10.1021/jo201334n

10. Malkov, A. V.; Mariani, A.; MacDougal, K. N.; Kočovský, P. Org. Lett. 2004, 6, 2253. doi:10.1021/ol049213+

11. Malkov, A. V.; Vranková, K.; Sigerson, R. C.; Stončius, S.; Kočovský, P. Tetrahedron 2009, 65, 9481. doi:10.1016/j.tet.2009.08.048

12. Baudequin, C.; Chaturvedi, D.; Tsogoeva, S. B. Eur. J. Org. Chem. 2007, 2623. doi:10.1002/ejoc.200700058

13. Wang, Z.; Ye, X.; Wei, S.; Wu, P.; Zhang, A.; Sun, J. Org. Lett. 2006, 5, 999. doi:10.1021/ol060112g

14. Xiao, Y.-C.; Wang, C.; Yao, Y.; Sun, J.; Chen, Y.-C.

Angew. Chem., Int. Ed. 2011, 50, 10661. doi:10.1002/anie.201105341

15. Wu, X.; Li, Y.; Wang, C.; Zhou, L.; Lu, X.; Sun, J. Chem.-Eur. J. 2011, 17, 2846. doi:10.1002/chem.201003105

16. Zheng, H.; Deng, J.; Lin, W.; Zhang, X. Tetrahedron Lett. 2007, 48, 7934. doi:10.1016/j.tetlet.2007.09.064

17. Jiang, J.; Chen, X.; Zheng, Y.; Xue, Z.; Shu, C.; Yuan, W.; Zhang, X. Angew. Chem., Int. Ed. 2011, 50, 7304. doi:10.1002/anie.201102150

18. Guizzetti, S.; Benaglia, M. Process for the stereoselective reduction of ketoimines catalysed by trichlorosilane. WO Pat. Appl. 2009/068284 A3, June 4, 2009.

19. Guizzetti, S.; Benaglia, M.; Cozzi, F.; Annunziata, R. Tetrahedron 2009, 65, 6354. doi:10.1016/j.tet.2009.06.015

20. Guizzetti, S.; Benaglia, M.; Rossi, S. Org. Lett. 2009, 11, 2928. doi:10.1021/ol900945h

21. Guizzetti, S.; Benaglia, M.; Biaggi, C.; Celentano, G. Synlett 2010, 134. doi:10.1055/s-0029-1218541

22. Guizzetti, S.; Benaglia, M.; Bonsignore, M.; Raimondi, L. Org. Biomol. Chem. 2011, 9, 739. doi:10.1039/c0ob00570c

23. Bonsignore, M.; Benaglia, M.; Annunziata, R.; Celentano, G. Synlett 2011, 1085. doi:10.1055/s-0030-1259941

24. Akiyama, T. Chem. Rev. 2007, 107, 5744. doi:10.1021/cr068374j

25. Terada, T. Chem. Commun. 2008, 4097. doi:10.1039/b807577h

26. Yu, J.; Shi, F.; Gong, L.-Z. Acc. Chem. Res. 2011, 44, 1156. doi:10.1021/ar2000343

27. Lu, Y.; Johnstone, T. C.; Arndtsen, B. A. J. Am. Chem. Soc. 2009, 131, 11284. doi:10.1021/ja904185b

28. Matsumura, Y.; Ogura, K.; Kouchi, Y.; Iwasaki, F.; Onomura, O. Org. Lett. 2006, 17, 3789. doi:10.1021/ol0613822

29. Leach, A. R. Molecular Modelling - principles and applications, 2nd ed.; Pearson Education: Prentice Hall, New Jersey, USA, 2001.

30. Zhao, Y.; Truhlar, D. G. Theor. Chem. Acc. 2008, 120, 215. doi:10.1007/s00214-007-0310-x

31. Mahlau, M.; List, B. Angew. Chem., Int. Ed. 2013, 52, 518. doi:10.1002/anie.201205343

32. MacroModel, 9.9; Schrödinger: New York, USA, 2011

33. Gaussian 09, Revision A.1; Gaussian, Inc: Wallingford, CT, 2009.

\section{License and Terms}

This is an Open Access article under the terms of the Creative Commons Attribution License

(http://creativecommons.org/licenses/by/2.0), which permits unrestricted use, distribution, and reproduction in any medium, provided the original work is properly cited.

The license is subject to the Beilstein Journal of Organic Chemistry terms and conditions:

(http://www.beilstein-journals.org/bjoc)

The definitive version of this article is the electronic one which can be found at:

doi:10.3762/bjoc. 9.71 